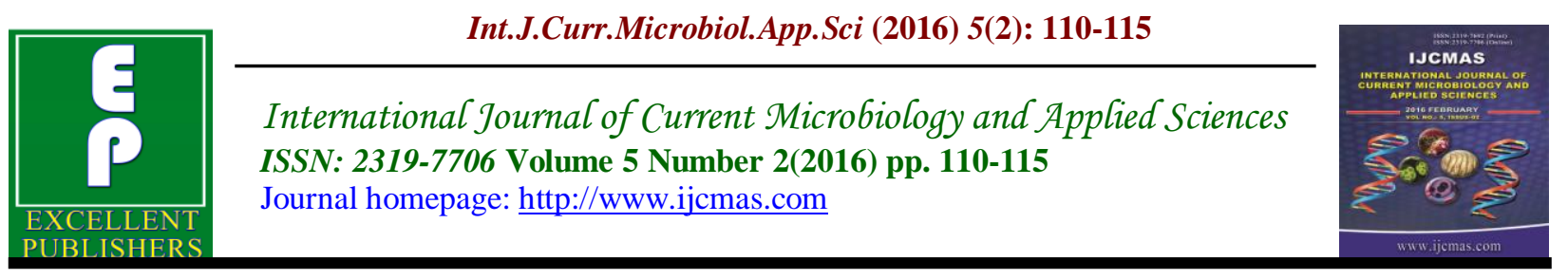

Original Research Article

doi: http://dx.doi.org/10.20546/ijcmas.2016.502.012

\title{
Bacterial Diarrhea in Antananarivo: Place of Salmonella spp and Shigella spp in Stool Culture
}

\author{
Andry Maharo Andrianarivelo ${ }^{1 *}$, Lalaina Mamenosoa Rakotondraoelina ${ }^{1}$, \\ Arthur Bien Aimé Ratsimbazafy ${ }^{2}$, Tojoniaina Herinjaka Andriamandimbisoa ${ }^{1}$, Solofo \\ Sarah Rafaramalala ${ }^{1}$, Christian Rafalimanana ${ }^{1}$ and Andry Rasamindrakotroka ${ }^{1}$ \\ ${ }^{1}$ Department of Biology, Faculty of Medicine Antananarivo, Madagascar \\ ${ }^{2}$ Department mother and child, Faculty of Medicine Antananarivo, Madagascar \\ *Corresponding author
}

\begin{tabular}{|c|c|}
\hline & A B S T R A C T \\
\hline & In 2008 , diarrhea was the second main cause of consultation in health centers in \\
\hline Keywords & Madagascar.We conducted a retrospective and descriptive study spanning 10 \\
\hline $\begin{array}{l}\text { Stool } \\
\text { culture, }\end{array}$ & laboratory of Microbiology University Hospital Joseph Ravoahangy \\
\hline $\begin{array}{l}\text { culture, } \\
\text { epidemiology, }\end{array}$ & $\begin{array}{l}\text { Andrianavalona (HU-JRA) Antananarivo Madagascar. The purpose of this work is } \\
\text { to describe the epidemiology of salmonellosis and shigellosis found at the HU-JRA }\end{array}$ \\
\hline $\begin{array}{l}\text { Salmonella spp, } \\
\text { Shigella spp, }\end{array}$ & $\begin{array}{l}\text { Antananarivo. The variables selected and used for the study were the patient age, } \\
\text { the season, the macroscopic appearance of stools and stool culture results. During }\end{array}$ \\
\hline Antananarivo & $\begin{array}{l}\text { the } 10 \text { years, } 576 \text { stools specimens arrived in the laboratory. We found } 34 \text { cases of } \\
\text { Salmonella spp }(5.89 \%) \text { and } 7 \text { cases of Shigella spp }(1.21 \%) .26 \text { cases of }\end{array}$ \\
\hline Article Info & $\begin{array}{l}\text { Salmonella spp were found to the summer season. The average age of infected } \\
\text { patients was } 18 \text { years. In two thirds of cases, the stool was not slimy and not bloody }\end{array}$ \\
\hline $\begin{array}{l}\text { Accepted: } \\
\text { 10 January } 2015 \\
\text { Available Online: } \\
\text { 10, February } 2016\end{array}$ & $\begin{array}{l}\text { to Salmonella spp. Shigella spp was seen especially in patients who have bloody or } \\
\text { mucoid-bloody stools. Diarrheal diseases caused by Salmonella spp and Shigella } \\
\text { spp touch especially children and young adults in Antananarivo. The appearance of } \\
\text { slimy and/or bloody stools is not always in favor of a Salmonella spp or Shigella } \\
\text { spp infection but we also have to look for other bacterial, parasitic or viral causes. }\end{array}$ \\
\hline
\end{tabular}

\section{Introduction}

According to WHO (World Health Organisation), diarrhea is defined as soft liquid stool with high frequency, at least three times a day (WHO, 1995). It is always a major cause of morbidity and mortality (Noel, J.S. et al., 1994).

In developing countries, mortality caused by diarrhea is frequent and acute gastro enteritis is responsible for a high morbidity, leading to multiple medical consultations and hospitalizations (Glass, R.I. et al., 1996 and Wit, M.A. et al., 2001).

Bacteriological examination of stool is often used for bacteriological diagnosis of acute or 
chronic diarrhea. Industrialized countries have a fewer percentage of Bacterial diarrhea compared with high percentage in developing countries, especially during summer (Ono, K. et al., and Alam, M. et al., 2003).

In Madagascar, water-borne and food origins diseases are common in families from urban and rural areas. In 2008, diarrhea was the second main cause of consultation in health centers (WHO), and $22 \%$ of child deaths were due to diseases related to diarrhea. (Direction de la veille sanitaire et de la surveillance épidémiologique à Madagascar. 2012).

Few studies have focused on bacterial diarrhea by Salmonella spp and Shigella spp in Antananarivo. In order to update knowledge on the epidemiology of salmonellosis and shigellosis found in feces during stool culture, we have conducted a retrospective and descriptive study about hospitalized patients or external patients, in the laboratory of Microbiology University Hospital Joseph Ravoahangy Andrianavalona (HU-JRA) Antananarivo Madagascar, for the last10 years (2005 to 2014).

The purpose of this study is to describe the epidemiology of salmonellosis and shigellosis experimented at the HU-JRA Antananarivo.

\section{Materials and Methods}

This is a retrospective and descriptive study for 10 years from January 2005 to December 2014 at the Laboratory of Microbiology of the University Hospital Joseph Ravoahangy Andrianavalona (HU-JRA) Antananarivo, the biggest academic hospital located in the capital of Madagascar.
All demands for standard bacteriological examination of stools were registered in the laboratory. No application has been excluded.

The variables selected and used for the study were the patient age, the season, the macroscopic appearance of stools and stool culture results.

The laboratory has a protocol for all patients who request a standard bacteriological examination of stools at the laboratory.

The stool is collected upon emission in a sterile pot. We must choose a saddle fragment size of a walnut selecting purulent or bloody or slimy areas and take the fragment with a spatula or, with a clean spoon and transfer it to the sterile pot. We must close the pot.

A rectal swab will be performed in infants and small children.

The levy should be immediately sent to the laboratory or stored for a maximum overnight at $4{ }^{\circ} \mathrm{C}$ to prevent from desiccation and commensal bacteria and yeasts.

All stool culture must systematically implement the Salmonella spp and Shigella spp research. The laboratory proceeded to stool cultivation on selective environment isolation agar SS and Hektoen, associated with an enrichment agar (MuellerKauffmann). Then, the enrichment on selective agar was transplanted after 3 to 6 hours of incubation at $37^{\circ} \mathrm{C}$ to prevent from commensal bacteria proliferation which are less developed past that time.

Campylobacter spp and Yersinia enterocolitica research are not performed in our study. 
The cultures are incubated during 48 hours in micro-aerophilic environment. Identification was done on the Api $20 \mathrm{E}$ gallery. Data were collected and analyzed on Excel.

\section{Results and Discussion}

Our study allowed having information about Salmonella spp and Shigella spp which are responsible for bacterial diarrhea after having realized a stool culture, in a university hospital in Antananarivo for 10 years. During the study, 576 stools specimens arrived in bacteriology laboratory of the HU-JRA Antananarivo.

Requests for stool culture are more frequent in November, December and January that correspond to the summer season in Madagascar (Figure 1).

Two thirds of cases $(66 \%)$ of Salmonella $s p p$ were found in November, December and January (Figure 2).

It is interesting that we observed an increase about the number of Salmonella diarrhea during the summer (26 cases). The peak incidence of stool culture and salmonellosis cases is likely related to rising water causing floods and also breaking the cold chain. This finding was confirmed by other authors as bacterial infections due to Salmonella peaked during the summer, but this observation may be dependent on the region studied and also weather (Verena, W. et al., National reference center for Salmonella and Shigella in Belgium. 2002. And Courouble, G. et al., 2000).

Regarding the results of stool examinations, we found 34 cases of Salmonella spp (5.89\%) and 7 cases of Shigella spp $(1.21 \%)$ with a total of positive case of $7.10 \%$. This number is very low compared to the number of requests. So, we must also consider other causes of diarrhea such as other bacteria, parasites and viruses. The stool culture can be faulted although diarrhea is important. Sometimes, the only repeating examination can highlight a Shigella or Salmonella.

Our patients were in age from seven days to 89 years with a median age of 8.42 years. The age group of 2-15 years predominates with 166 requests.

The average age of infected patients was 18 years. Salmonella spp infected mainly the age group of 2-30 years and Shigella spp was seen especially in the age group of 2-15 years (Table 1).

Infection with Salmonella spp is rare for less than 2 years and for more than 50 years. Salmonella spp primarily infects the age group of 2-30 years. The incidence of salmonellosis is very underestimated, particularly in pediatrics, because of the nature of many benin gastroenteritis Salmonella in which the stool culture is not necessary. And for children, the bacterial inoculum necessary to cause diarrhea is less and the germ is often in low abundance in the stool (Gendrel, D. 1998).

About 50\% of children under 5 years and $16 \%$ of adults excrete the germ in their stool for several weeks after acute diarrhea caused by Salmonella (Buchwald, D.S, 1984). The infective dose of Salmonella is low especially in children. Also any carrier, even if it excretes a small amount of bacteria in the stool, is a potential source of contagion, which poses a major problem for children in community (Gendrel, D. 1998). Salmonella diarrhea is more common in developing countries and would be linked to poor conditions of individual and collective hygiene. According to the National Reference Centre for Salmonella and 
Shigella belgian, 2002, the largest number of confirmed cases of salmonellosis was found in children under 5 years $(41 \%)$. There are over two thousand two hundred Salmonella serotypes but $15 \%$ of the strains account for $85 \%$ of infections (Courouble, G. et al.,).

Table.1 Distribution of Salmonella spp and Shigella spp by Age, Hospitalisation and the Number of Positive Cases

\begin{tabular}{lccccc}
\cline { 3 - 6 } Years & $\begin{array}{c}\text { Number of } \\
\text { requests }\end{array}$ & $\begin{array}{c}\text { Number of } \\
\text { positive cases }\end{array}$ & Hospitalized & $\begin{array}{c}\text { Number of } \\
\text { positive cases }\end{array}$ & Hospitalized \\
$<2$ & 64 & 0 & 0 & 1 & 0 \\
{$[2-15[$} & 166 & 11 & 6 & 4 & 1 \\
{$[15-30[$} & 106 & 13 & 7 & 1 & 0 \\
{$[31-50[$} & 124 & 9 & 4 & 0 & 0 \\
$>50$ & 116 & 1 & 0 & 1 & 0 \\
Total & 576 & 34 & 17 & 7 & 1 \\
\hline
\end{tabular}

Table.2 Stool Appearance by Germs

\begin{tabular}{lccc}
\hline Stool appearance & Number & Salmonella spp & Shigellaspp \\
\hline Not slimy and not bloody & 404 & 22 & 0 \\
Bloody & 42 & 1 & 2 \\
Slimy & 96 & 10 & 0 \\
Slimy and bloody & 34 & 1 & 5 \\
Total & 576 & 34 & 7 \\
\hline
\end{tabular}

Figure.1 Distribution of Stool Culture Demand Per Month

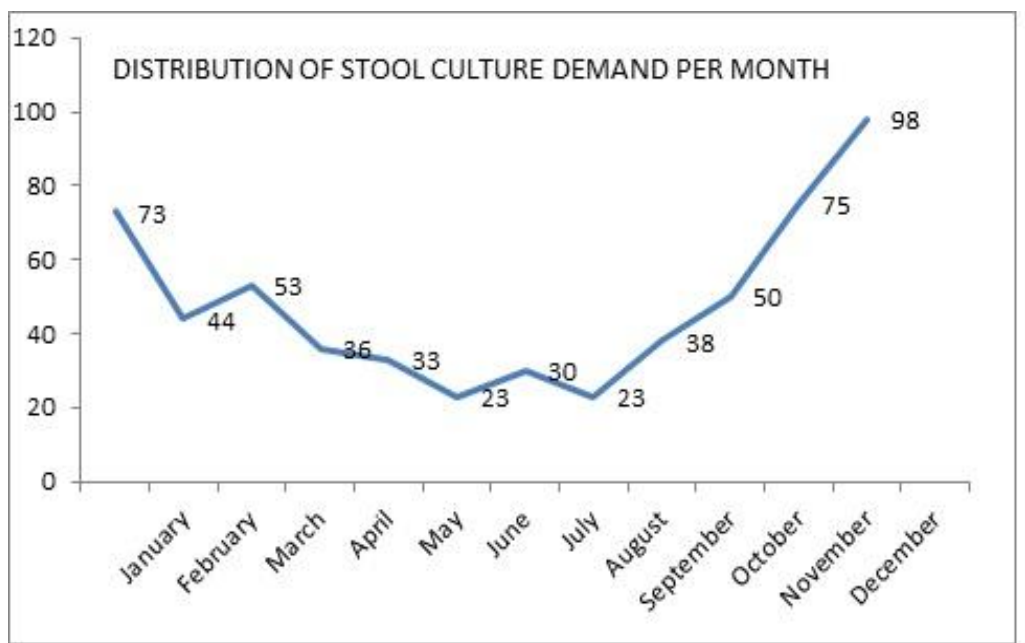


Figure.2 Distribution of the Results Per Month

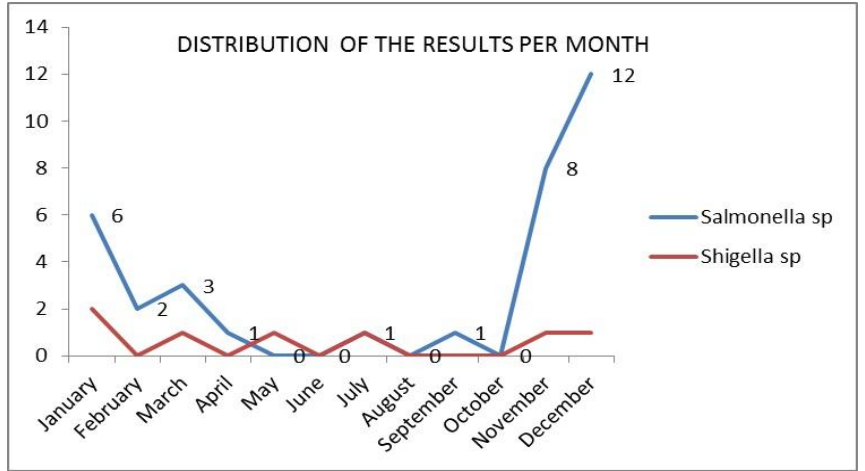

The bacillary dysentery can also be caused by Shigella. In our study, Shigella spp is seen especially in the age group of 2-15 years. Shigellosis are not confined to developing countries. They are responsible for many diarrhea in developed countries and mainly hit the child. Mortality, high in the first countries, is not least in the West. Shigellosis is not only an import disease, there are also outbreaks in France, often graves.(Cerf, M., 1996).Strains causing the most severe forms with high mortality are Shigella dysenteriae (especially serotype 1), and Shigella flexneri. Shigellosis are one of the most varieties of communicable diarrhea. The inoculum required is very small (ten bacilli generate symptoms in $10 \%$ of volunteers) and small intra family epidemics in communities around the initial cases are very common.(Guerrero, L. et al., 1994). 50\% of patients infected with Salmonella spp and $14 \%$ of patients infected with Shigella spp hospitalized (Table 1). This implies that one can always catch Salmonella and Shigella as well as in community or in hospital.

About the appearance of stool, the stool was not slimy and not bloody in $70 \%$ of applications (404 patients). In two thirds of cases, the stool was not slimy and not bloody for Salmonella spp with 22 cases (Table 2).The stool examination is usually required to investigate the cause of a supposed bacterial diarrhea, whether it is slimy or bloody or not slimy not bloody. In our study, non-slimy and non-bloody stools are found in $70 \%$ of applications. The case of diarrhea is highly variable. It may be a banal diarrhea healing spontaneously or, conversely, dysentery with shock and neurological manifestations.

Shigella spp was seen especially in patients who have bloody or slimy and bloody stools (Table 2). The Shigella infection can be serious, with real vital risk that requires them to seek stool culture as soon as you suspect for two reasons. Indeed, Shigella diarrhea should be treated with antibiotic therapy. It is therefore important to have a susceptibility due to the emergence of resistant strains. The other reason is epidemiological, we must be reported to health authorities because the family epidemics collective risk is real. The Shigella research, however, is not always easy for stool culture because the number of germs may be low, so we must rebuild stool culture for several times. Finally, asymptomatic carriage would be much more common than was thought until now. (Guerrero, L. et al., 1994)

In conclusion, diarrheal diseases caused by Salmonella spp and Shigella spp represent only $7.10 \%$ requests stool in our study and especially touch children and young adults 
in Antananarivo. Diarrhea is a very common reason for consultation, particularly in developing countries. The appearance of slimy and/or bloody stools is not always in favor of a Salmonella spp or Shigella spp infection but we also have to look for other bacterial, parasitic or viral causes.

\section{References}

Alam, M., Akhtar, Y.N., Ali, S.S., et al.,. 2003. Seasonal variation in bacterial pathogens isolated from stool samples in Karachi, Pakistan. J Pak Med Assoc, 53: 125-129

Buchwald, D.S., Blaser, M.J.. 1984. A review of human salmonellosis, duration of excretion following infection with non typhi Salmonella. Rev Infect Dis, 6: 345-356

Cerf, M., Hagiage, M. 1996. Diarrhées aiguës d'origine infectieuse. Encyclopédie MédicoChirurgicale $9061 \mathrm{~A}^{10}: 1-20$. Épidémie de shigellose en région parisienne. Bull EpidHebd, 35: 153

Courouble, G., Dufillot, D., Sans, A., Malpote, E., Berchel, C., Nicolas, M. 2000. Enquête sur les gastro-entérites aiguës infantiles au CHU de Pointe-à-Pitre/Abymes, Guadeloupe, de novembre 1997 à mars 1998. Bull Soc Pathol Exo,93: 58-61

Direction de la veille sanitaire et de la surveillance épidémiologique à Madagascar. 2012. La diarrhée : risque de négligence. Bulletin périodique d'informations, Ministère de la santé publique de Madagascar, Numéro 14

Gendrel, D. 1998. Agents infectieux à l'origine des diarrhées aiguës. Médecine thérapeutique / Pédiatrie, Vol 1 Numéro 1

Glass, R.I., Kilgore, P.E., Holman, R.C., Jin, S.,
Smith, J.C., Woods, P.A., et al.,. 1996. The epidemiology of Rotavirus diarrhea in the United States: surveillance and estimates of disease burden. J Infect Dis, 174 Supp 11: S5-11.

Guerrero, L., et al.,. 1994. Asymptomatic shigella infections in a cohort of Mexican children younger than 2 years of age. Pediatr Infect Dis J, 13: 597-602

National reference center for Salmonella and Shigella.2002. Annual report on human Salmonella and Shigella in Belgium, Institute of public health.

Noel, J.S., Parker, S., Choules, K., Phillips, A.D., Walker-Smith, J., and Cubitt, W.D.. 1994. Impact of Rotavirus infection on a pediatric hospital in the east end of London. J Clin Pathol, 47: 67-70

Ono, K., Rai, S.K., Chikahira, M., et al.,. 2011. Seasonal distribution of enteropathogens detected from diarrheal stool and water samples collected in Kathmandu, Nepal. Southeast Asian J Trop Med Public Health, 32: 520-526

Verena, W., Jan, K., Dennis, T., Benedikt, W., Henner, M., Hermann, J.G. 2011. Gastroenteritis in childhood: a retrospective study of 650 hospitalized pediatric patients. International Journal of Infectious Diseases, 15: 401-407.

Wit, M.A., Koopmans, M.P., Kortbeek, L.M., Van Leeuwen, N.J., Vinjé, J., Van Duynhoven, Y.T. 2001. Etiology of gastroenteritis in sentinel general practices in the Netherlands. Clin Infect Dis, 1; 33(3): 280-8.

World Health Organization: the treatment of diarrhea. 1995. A Manual for Physicians and Other Senior Health Workers. Geneva, World Health Organization.

\section{How to cite this article:}

Andry Maharo Andrianarivelo, Lalaina Mamenosoa Rakotondraoelina, Arthur Bien Aimé Ratsimbazafy, Tojoniaina Herinjaka Andriamandimbisoa, Solofo Sarah Rafaramalala, Christian Rafalimanana and Andry Rasamindrakotroka. 2016. Bacterial Diarrhea in Antananarivo: Place of Salmonella spp and Shigella spp in Stool Culture. Int.J.Curr.Microbiol.App.Sci. 5(2): 110115. doi: http://dx.doi.org/10.20546/ijcmas.2016.502.012 